\title{
Sorafenib and the medical treatment of hepatocellular carcinoma
}

\author{
Antoine Galmiche, Bruno Chauffert, Jean-Claude Maziere, Jean-Claude Barbare
}

CHU d'Amiens, Université de Picardie Jules Verne, 80054 Amiens Cedex, France.

Corresponding author: Antoine Galmiche, MD-PhD, Service de Biochimie, CHU Nord Amiens, 1 Place Victor Pauchet, 80054 Amiens Cedex, France, Tel: 033-(0)322668446, Fax: 033-(0)322668593, E-mail: Galmiche.Antoine@chu-amiens.fr

Received: 2011-08-22

DOI : $10.5430 /$ jst.v1n3p132

Accepted: 2011-09-12

URL: http://dx.doi.org/10.5430/ist.v1n3p132

\section{Abstract:}

Hepatocellular carcinoma (HCC) is the most frequent form of primary liver tumor. HCC is characterized by its occurrence in a context of chronic liver disease. The burden of HCC is expected to increase in the coming decade, principally because of its rising incidence. Although radical treatments are available when a unique tumor of small size is found, HCC is more often diagnosed at an advanced stage. Classical schemes for the treatment of advanced HCC have been recently challenged with the introduction of sorafenib (Nexavar ${ }^{\circledR}$ ), a new reference treatment for advanced HCC. The report of the SHARP clinical trial, showing for the first time the efficacy of sorafenib in advanced HCC, became one of the most cited reports in the cancer literature (Highly cited cancer papers, 2008-2010, Nature Medicine 2011: 17: 280). Sorafenib is an inhibitor of oncogenic kinases that has recently been approved as the reference treatment for advanced HCC. Sorafenib affords a modest gain in survival by delaying the progression of HCC. In the absence of validated biomarkers that would predict its efficacy, several questions pertaining to its indications and the follow-up of this treatment remain unanswered. Here, we review the essential facts about sorafenib and its use in HCC. We also put emphasis on the actual research perspectives that could improve HCC treatment based on sorafenib.

\section{Key Words:}

Hepatocellular carcinoma; Sorafenib; Targeted therapy; Kinases; Apoptosis

\section{Sorafenib as a Blocker of Oncogenic Kinases}

Sorafenib was originally identified in a search for inhibitors directed against the RAF kinases. The three Ser/Thr kinases of the RAF family (A-RAF, B-RAF, and C-RAF/RAF-1) are essential components of the ubiquitous signalling cascade RAS-RAF-MEK-ERK. This cascade plays a fundamental role as a relay for the transmission of trophic signals from receptors present at the cell surface. ${ }^{1}$ Two members of this family in particular, B-RAF and C-RAF, are among the most-studied and best-described. Although C-RAF (formerly Raf-1) has attracted most attention for historical reasons, B-RAF recently gained some importance after it was found that a single activating mutation, B-RAF V600E, is detected in melanoma, and to a lower extent, in colorectal tumors. ${ }^{1}$ The oncogenic potential of the RAF cascade has been established in various transgenic animal models, in which tumors appear following the introduction of a transgene encoding an activated version of RAS or RAF. ${ }^{1}$

Following the evidence demonstrating a crucial role of RAF kinases in the oncogenic transformation, sorafenib was quickly tested in vitro and found to decrease phosphorylated ERK levels in various tumor cell lines. ${ }^{2}$ Crystal structure of the catalytic domain of B-RAF in complex with sorafenib shows that sorafenib is a so-called type 2 blocker of these kinases, that binds a region close to the one occupied by ATP rather than the ATP-binding pocket. Sorafenib binds RAF 
kinases in their inactive conformation and prevents their activation in vitro. ${ }^{3}$ In living cells however, sorafenib is a weak blocker of RAF kinases, or even a paradoxical activator of the RAF kinases in a context where they are pre-activated, for example by an activated RAS GTPases. ${ }^{4}$ In HCC tumors, such an activation of the C-RAF kinase was noticed in a model of human tumor xenografts, leading the authors to postulate that most of the efficacy of sorafenib in HCC might stem from the inhibition of kinases other than RAF. ${ }^{5}$ While sorafenib inhibits the receptor tyrosine kinases for the vascular endothelial growth factor (VEGF), platelet-derived growth factor $\beta$ (PDGF- $\beta$ ), FMS-like tyrosine kinase 3 (Flt3 ), or c-kit, ${ }^{2}$ it is not yet clear if the blockade of these receptors plays any role in the therapeutic efficacy of sorafenib. Consequently, the use of sorafenib in HCC offers a paradoxical situation of a so-called targeted therapy whose target(s) remain(s) to be identified.

\section{Clinical Use of Sorafenib in HCC}

The efficacy of sorafenib in HCC was first evidenced in the SHARP large phase 3 randomized clinical trial, with patients mainly recruited from North America and Europe, ${ }^{6}$ and latter confirmed independently in the Asia-Pacific study. ${ }^{7}$ In both studies, sorafenib was found to extend the survival of patients with advanced HCC, although the spectrum of etiologic factors was different, with a high prevalence of hepatitis B virus (HBV) in the Asian population compared to more frequent $\mathrm{HCV}$ infection and alcohol intoxication in Europe and North America. ${ }^{6,7}$ The results of the SHARP study established a landmark in HCC, because sorafenib became at that time the first systemic treatment with a proven efficacy in advanced HCC. HCC is a tumor that possesses the particularity of occurring almost systematically in patients with chronic liver disease (most often because of chronic alcohol intake, viral hepatitis or metabolic alterations). Initial doubts about the safety of sorafenib led to a restriction of its prescription only to patients with preserved hepatic function (in the SHARP and Asia Pacific studies, sorafenib was essentially prescribed to patients with Child-Pugh A status). Sorafenib was found to be overall safe, at least at doses of $400 \mathrm{mg}$ twice daily or less. The most common adverse effects include fatigue, diarrhea, rash, and hand-foot skin reaction. ${ }^{8}$ These side effects do not usually interfere with the prescription of sorafenib in HCC. On the basis of this safe profile, an extension of its prescription to patients with a more advanced deterioration of liver function has recently been advocated, although caution must be exerted. Sorafenib pharmacokinetics is not altered in patients with moderate hepatic insufficiency (Child-Pugh B status), but these patients are at higher risk of hepatic decompensation and general complications. ${ }^{9,}{ }^{10}$ For these patients, a protocol of dose escalation might be adequate to prevent potential complications. ${ }^{10}$

While the introduction of sorafenib was a breakthrough in the treatment HCC, its overall efficacy remains modest, with a gain of survival of only a few months. Furthermore, sorafenib essentially extends the survival of patients with HCC through its ability to slow tumor progression. ${ }^{6}$ Sorafenib induces few objective responses, a situation that renders the individual evaluation and the follow-up of the treatment complex. Standard guidelines for the assessment of response of tumors to cytotoxic chemotherapy, such as the RECIST (Response Evaluation Criteria in Solid Tumors) tool, ${ }^{11}$ are increasingly perceived as inadequate to assess the activity of sorafenib and other targeted therapies. For example, sorafenib eventually induces necrosis of some HCC, so the ratio of the area of necrosis over the tumor area might be more accurate than the simple measurement of tumor dimensions in order to determine the tumor response to treatment. ${ }^{9}$ 12 New parameters that would improve the follow up of patients receiving sorafenib are therefore eagerly awaited. Advanced imaging techniques will certainly be a helpful adjunct to the actual assessment schemes, because they permit an evaluation of changes in tumor density and vascularization, as well as the necrotic areas. ${ }^{13,14}$ Identification of the parameters that predict the efficacy of sorafenib is also a key objective for future research, as it is expected to help physicians to guide the prescription of sorafenib in HCC. High levels of activation of the RAF kinase pathway, measured through the phosphorylation of the downstream effector kinase ERK, are associated with a longer time to progression suggesting that HCC with high phosphorylation levels of ERK could be more sensitive to sorafenib. Interesting as it is, the use of this marker remains to be validated. Also, this type of analysis is performed by immunohistochemistry, and its application poses a problem of standardization. Any genotypic analysis that would predict the efficacy of sorafenib would be of great value to physicians in charge of HCC patients.

Another important question awaiting answers relates to the existence of the interaction(s) that might exist between sorafenib and other treatments for HCC, and in particular with treatments based on chemotherapeutic agents. Although systemic administration of these agents has been abandoned and is widely considered inefficient in HCC, chemotherapeutic drugs remain in use as active components of loco-regional treatment, particularly in association with tumor embolization. ${ }^{15}$ Transarterial chemoembolization (TACE) is used for locally advanced, unresectable HCC. This procedure extends the survival of patients with HCC compared to symptomatic treatments, but its potentially deleterious action on liver function implies the need to carefully select recipients. ${ }^{16,17}$ It is not yet clear if the patients that receive TACE could benefit from the prescription of sorafenib. ${ }^{18}$ A recent phase 3 clinical trial of sorafenib given to patients presenting with a response to TACE failed to show a clinical benefit of sorafenib. ${ }^{19}$ However, this failure might have 
resulted from an inadequate protocol, as it is currently unclear what could be the optimal scheme, either a combination or sequential treatment. The recent study of Pawlik, et al., suggesting that TACE and sorafenib can safely be coadministered, will certainly prompt further clinical studies to determine if sorafenib and TACE can offer interesting synergies in the clinical setting. ${ }^{20}$

\section{I mproving Efficacy of Sorafenib in HCC?}

Several authors have proposed possible strategies for the optimization of the effect of this treatment in HCC. While a comprehensive overview of these strategies is beyond the scope of our review, we would like to present two possible approaches to enforce the efficacy of sorafenib in HCC: i) optimizing the control of the kinome of the cancer cell via the association with other targeted therapies; ii) sensitizing HCC cells to sorafenib-induced apoptosis.

\section{Optimizing the control of the kinome of HCC cells}

Although relatively little is known about the kinome of HCC cells as opposed to normal hepatocytes, the efficacy of sorafenib as well as the many other targeted therapies currently in use or in development in other tumors provides a solid proof of concept for the utility of the control of the kinome in HCC. A major goal of the medical treatment of tumors is to identify the kinases to which cancer cells might be "addicted". ${ }^{21}$ Most studies to date have envisioned only the role of the main canonical kinase pathways that are altered in HCC progression, such as the RAF-MEK-ERK and the PI3KPKB-mTOR pathways. ${ }^{22}$ An efficient control of HCC cells might require the inhibition of these signaling cascades, but it is still unclear which option should be privileged: either a tight control of either one of these pathways, or a combined inhibition of both. In favour of the second possibility, a recent study examining secondary resistance to sorafenib in one HCC cell line found that an activated PI3K pathway renders these cells less sensitive to sorafenib, suggesting that these kinase cascades might to some extent stand in for the other. ${ }^{23}$ Accordingly, it has also been reported that the efficacy of sorafenib might be increased by combining it with an inhibitor of the oncogenic kinase mTOR. ${ }^{24}$ In support of the alternative strategy, Huyn, et al. reported a successful pre-clinical study combining sorafenib with another inhibitor of the RAF-MEK-ERK pathway, the MEK inhibitor AZD6244. ${ }^{5}$ The search for synergies between sorafenib and other targeted therapies is likely to become an intense research area. According to a recent review, there are currently more than 60 targeted therapies derived from the recent knowledge on cancer cell signalling. ${ }^{25}$

\section{Sensitizing HCC cells to sorafenib-induced apoptosis}

In multiple experimental systems consisting of cell cultures as well as animal models of HCC, sorafenib was found to not only block HCC cell proliferation and tumor angiogenesis, but also to promote tumor cell apoptosis. ${ }^{26}$ Tumor cell death is usually considered to be a desirable end-point for medical treatment of tumors, considering that it is an important parameter for tumor regression. How precisely sorafenib sensitizes HCC cells to apoptosis has been the focus of different studies. In addition to the direct blocking effect of pro-kinases such as the RAF kinases, sorafenib probably interferes with several aspects of HCC cell physiology. For example, it has been shown that sorafenib can induce both apoptosis and autophagy in human HCC cells through a mechanism involving endoplasmic reticulum stress. ${ }^{27}$ Irrespective of the mechanisms involved, apoptosis has been principally studied from the perspective of the regulation of BCL2 proteins, given the importance of these regulators in the mitochondrial phase of apoptosis. ${ }^{28}$ In HCC as well as in a variety of other cancer cells, sorafenib has been reported to shift the balance between pro- and anti-apoptotic proteins of the BCL2 family. Sorafenib reduces the expression of the anti-apoptotic protein MCL1. ${ }^{26}$ Sorafenib also functionally inactivates the other major anti-apoptotic proteins of this family, such as BCL2 and BCL-XL, although the mechanisms are indirect. It was for example reported that sorafenib prevents the inactivating phosphorylations that reduce the activity of the pro-apoptotic sensitizer protein BAD. ${ }^{29}$ More recently, sorafenib was also reported to induce the expression of some of the pro-apoptotic BH3-only proteins of the BCL2 family, such as PUMA or BIM. ${ }^{30}$ Altogether, sorafenib promotes the activity of pro-apoptotic proteins of the BCL2 family, and thereby sensitizes HCC cells toward apoptosis. The identification of BCL2 proteins as important protagonists in sorafenib-induced apoptosis offers important perspectives in terms of therapeutics. Indeed, new targeted therapies exploiting this control with the aim of directly manipulating the susceptibility of cancer cells to apoptosis have recently been introduced. ${ }^{31}$ The compound ABT-737, recently developed as an inhibitor of the anti-apoptotic proteins BCL2 and BCL-XL by the laboratory Abbott, was found to greatly sensitize HCC cells to sorafenib-induced apoptosis. ${ }^{29,32}$

\section{Open Questions and Future I ssues}

The introduction of sorafenib for the treatment of HCC has marked the entering of liver oncology into the era of targeted therapies. As previously mentioned, sorafenib offers a paradoxical situation because it is one of the earliest targeted therapies developed to counteract oncogenic kinases, and one for which the precise biologically relevant target(s) are not completely identified. Nevertheless, the demonstration that sorafenib was able to extend the survival of patients with HCC has significantly fostered research, and progress in the field is expected in the coming years. It is difficult to 
predict exactly what important advances will be made. However, as our knowledge on liver carcinogenesis keeps increasing, it might soon become possible to derive predictive biomarkers for the efficacy of sorafenib, as well as new treatments. Oncologists and hepatologists interested in HCC will certainly await these fundamental developments, considering their importance for the development of further HCC treatments, and in particular the emergence of personalized treatments based on the rational analysis of individual tumors.

Acknowledgements: We thank Zuzana Saidak for helpful comments regarding the manuscript.

Sources of Support: Région Picardie, Ligue contre le Cancer.

Conflicting Interest: Dr JC Barbare is a recipient of honoraria as clinical consultant for Bayer France. Other authors reported no conflict of interest.

\section{REFERENCES}

[1] Wellbrock C, Karasarides M, Marais R. The RAF proteins take centre stage. Nat Rev Mol Cell Biol. 2004 ; 5: 875-85. http://dx.doi.org/10.1038/nrm1498 PMid:15520807

[2] Wilhelm SM, Carter C, Tang L, Wilkie D, McNabola A, Rong H, et al. BAY 43-9006 exhibits broad spectrum oral antitumor activity and targets the RAF/MEK/ERK pathway and receptor tyrosine kinases involved in tumor progression and angiogenesis. Cancer Res 2004 ; 64: 7099-109. http://dx.doi.org/10.1158/0008-5472.CAN-04-1443 PMid:15466206

[3] Wan PT, Garnett MJ, Roe SM, Lee S, Niculescu-Duvaz D, Good VM, et al. Mechanism of activation of the RAF-ERK signaling pathway by oncogenic mutations of B-RAF. Cell 2004; 116, 855-867. http://dx.doi.org/10.1016/S0092-8674(04)00215-6

[4] Cox AD, Der CJ. The raf inhibitor paradox: unexpected consequences of targeted drugs. Cancer Cell. 2010; 17: 221-3. http://dx.doi.org/10.1016/j.ccr.2010.02.029 PMid:20227037

[5] Huynh H, Ngo VC, Koong HN, Poon D, Choo SP, Toh HC, et al. AZD6244 enhances the anti-tumor activity of sorafenib in ectopic and orthotopic models of human hepatocellular carcinoma (HCC). J Hepatol 2010; 52: 79-87. http://dx.doi.org/10.1016/j.jhep.2009.10.008 PMid:19910069

[6] Llovet JM, Ricci S, Mazzaferro V, Hilgard P, Gane E, Blanc JF, et al. Sorafenib in advanced hepatocellular carcinoma. N Engl J Med 2008; 359: 378-90. http://dx.doi.org/10.1056/NEJMoa0708857 PMid:18650514

[7] Cheng AL, Kang YK, Chen Z, Tsao CJ, Qin S, Kim JS, et al. Efficacy and safety of sorafenib in patients in the Asia-Pacific region with advanced hepatocellular carcinoma: a phase III randomised, double-blind, placebo-controlled trial. Lancet Oncol. 2009 ; $10: 25-34$. http://dx.doi.org/10.1016/S1470-2045(08)70285-7

[8] Strumberg D, Clark JW, Awada A, Moore MJ, Richly H, Hendlisz A, et al. Safety, pharmacokinetics, and preliminary antitumor activity of sorafenib: a review of four phase I trials in patients with advanced refractory solid tumors. Oncologist. 2007; 12: 426-37. http://dx.doi.org/10.1634/theoncologist.12-4-426 PMid:17470685

[9] Abou-Alfa GK, Schwartz L, Ricci S, Amadori D, Santoro A, Figer A, et al. Phase II study of sorafenib in patients with advanced hepatocellular carcinoma. J Clin Oncol. 2006; 24: 4293-300. http://dx.doi.org/10.1200/JCO.2005.01.3441 PMid:16908937

[10] Miller AA, Murry DJ, Owzar K, Hollis DR, Kennedy EB, Abou-Alfa G, et al. Phase I and pharmacokinetic study of sorafenib in patients with hepatic or renal dysfunction: CALGB 60301. J Clin Oncol. 2009; 27: 1800-5. http://dx.doi.org/10.1200/JCO.2008.20.0931 PMid:19255312 PMCid:2668705

[11] Therasse P, Arbuck SG, Eisenhauer EA, Wanders J, Kaplan RS, Rubinstein L, et al. New guidelines to evaluate the response to treatment in solid tumors. European Organization for Research and Treatment of Cancer, National Cancer Institute of the United States, National Cancer Institute of Canada. J Natl Cancer Inst. 2000; 92: 205-16. http://dx.doi.org/10.1093/jnci/92.3.205 PMid:10655437

[12] Lencioni R, Llovet JM. Modified RECIST (mRECIST) assessment for hepatocellular carcinoma. Semin Liver Dis. 2010 ; 30 : 52-60. http://dx.doi.org/10.1055/s-0030-1247132 PMid:20175033

[13] Horger M, Lauer UM, Schraml C, Berg CP, Koppenhöfer U, Claussen CD, et al. Early MRI response monitoring of patients with advanced hepatocellular carcinoma under treatment with the multikinase inhibitor sorafenib. BMC Cancer. 2009; 9:208. http://dx.doi.org/10.1186/1471-2407-9-208 PMid:19558720 PMCid:2714320

[14] Faivre S, Zappa M, Vilgrain V, Boucher E, Douillard JY, Lim HY, et al. Changes in tumor density in patients with advanced hepatocellular carcinoma treated with sunitinib. Clin Cancer Res. 2011; 17: 4504-12. 
http://dx.doi.org/10.1158/1078-0432.CCR-10-1708 PMid:21531821

[15] Bruix J, Sherman M. Mangement of Hepatocellular Carcinoma : an Update. Hepatology 2011; 53: 1020-2. http://dx.doi.org/10.1002/hep.24199 PMid:21374666 PMCid:3084991

[16] Lo CM, Ngan H, Tso WK, Liu CL, Lam CM, Poon RT, et al. Randomized controlled trial of transarterial lipiodol chemoembolization for unresectable hepatocellular carcinoma. Hepatology. 2002; 35: 1164-71. http://dx.doi.org/10.1053/jhep.2002.33156 PMid:11981766

[17] Llovet JM, Real MI, Montaña X, Planas R, Coll S, Aponte J, et al. Arterial embolisation or chemoembolisation versus symptomatic treatment in patients with unresectable hepatocellular carcinoma: a randomised controlled trial. Lancet. 2002; 359: $1734-9$. http://dx.doi.org/10.1016/S0140-6736(02)08649-X

[18] Abou-Alfa GK. TACE and Sorafenib: A Good Marriage? J Clin Oncol. 2011 [Epub ahead of print]

[19] Kudo M, Imanaka K, Chida N, Nakachi K, Tak WY, Takayama T, et al. Phase III study of sorafenib after transarterial chemoembolisation in Japanese and Korean patients with unresectable hepatocellular carcinoma. Eur J Cancer. 2011; 47: $2117-27$. http://dx.doi.org/10.1016/j.ejca.2011.05.007 PMid:21664811

[20] Pawlik TM, Reyes DK, Cosgrove D, Kamel IR, Bhagat N, Geschwind JF. Phase II Trial of Sorafenib Combined With Concurrent Transarterial Chemoembolization With Drug-Eluting Beads for Hepatocellular Carcinoma. J Clin Oncol. 2011 [Epub ahead of print]

[21] Luo J, Solimini NL, Elledge SJ. Principles of cancer therapy: oncogene and non-oncogene addiction. Cell. 2009 ; 136 : 823-37. http://dx.doi.org/10.1016/j.cell.2009.02.024 PMid:19269363 PMCid:2894612

[22] Whittaker S, Marais R, Zhu AX. The role of signaling pathways in the development and treatment of hepatocellular carcinoma. Oncogene 2010; 29: 4989-5005. http://dx.doi.org/10.1038/onc.2010.236 PMid:20639898

[23] Chen KF, Chen HL, Tai WT, Feng WC, Hsu CH, Chen PJ, at al. Activation of phosphatidylinositol 3-kinase/akt signaling pathway mediates acquired resistance to sorafenib in hepatocellular carcinoma cells. J Pharmacol Exp Ther 2011; 337: 155-61. http://dx.doi.org/10.1124/jpet.110.175786 PMid:21205925

[24] Newell P, Toffanin S, Villanueva A, Chiang DY, Minguez B, Cabellos L, et al. Ras pathway activation in hepatocellular carcinoma and antitumoral effect of combined sorafenib and rapamycin in vivo. J Hepatol. 2009; 51: 725-33. http://dx.doi.org/10.1016/i.jhep.2009.03.028 PMid:19665249 PMCid:2970800

[25] Villanueva A, Llovet JM. Targeted therapies for hepatocellular carcinoma. Gastroenterology 2011; 140: $1410-26$. http://dx.doi.org/10.1053/j.gastro.2011.03.006 PMid:21406195

[26] Liu L, Cao Y, Chen C, Zhang X, McNabola A, Wilkie D, et al. Sorafenib blocks the RAF/MEK/ERK pathway, inhibits tumor angiogenesis, and induces tumor cell apoptosis in hepatocellular carcinoma model PLC/PRF/5. Cancer Res 2006; 66: $11851-8$. http://dx.doi.org/10.1158/0008-5472.CAN-06-1377 PMid:17178882

[27] Shi YH, Ding ZB, Zhou J, Hui B, Shi GM, Ke AW, et al. Targeting autophagy enhances sorafenib lethality for hepatocellular carcinoma via ER stress-related apoptosis. Autophagy 2011; 7 [Epub ahead of print]

[28] Youle RJ, Strasser A. The BCL-2 protein family: opposing activities that mediate cell death. Nat Rev Mol Cell Biol 2008; 9: 47-59. http://dx.doi.org/10.1038/nrm2308 PMid:18097445

[29] Galmiche A, Ezzoukhry Z, François C, Louandre C, Sabbagh C, Nguyen-Khac E, et al. BAD, a proapoptotic member of the BCL2 family, is a potential therapeutic target in hepatocellular carcinoma. Mol Cancer Res 2010; 8: 1116-25. http://dx.doi.org/10.1158/1541-7786.MCR-10-0029 PMid:20647330

[30] Fernando J, Sancho P, Fernández-Rodriguez CM, Lledó JL, Caja L, Campbell J, et al. Sorafenib sensitizes hepatocellular carcinoma cells to physiological apoptotic stimuli. J Cell Physiol. 2011 [Epub ahead of print]

[31] Oltersdorf T, Elmore SW, Shoemaker AR, Armstrong RC, Augeri DJ, Belli BA, et al. An inhibitor of Bcl-2 family proteins induces regression of solid tumours. Nature 2005; 435: 677-81. http://dx.doi.org/10.1038/nature03579 PMid: 15902208

[32] Hikita H, Takehara T, Shimizu S, Kodama T, Shigekawa M, Iwase K, et al. The Bcl-xL inhibitor, ABT-737, efficiently induces apoptosis and suppresses growth of hepatoma cells in combination with sorafenib. Hepatology 2010; 52: 1310-21. http://dx.doi.org/10.1002/hep.23836 PMid:20799354 